This item was submitted to Loughborough's Research Repository by the author.

Items in Figshare are protected by copyright, with all rights reserved, unless otherwise indicated.

\title{
Attitudinal and socio-demographic effects on willingness to pay for water services and actual payment behaviour
}

PLEASE CITE THE PUBLISHED VERSION

http://dx.doi.org/10.1080/1573062X.2010.509437

PUBLISHER

(c) Taylor \& Francis

VERSION

AM (Accepted Manuscript)

LICENCE

CC BY-NC-ND 4.0

\section{REPOSITORY RECORD}

Mugabi, Josses, and Sam Kayaga. 2019. "Attitudinal and Socio-demographic Effects on Willingness to Pay for Water Services and Actual Payment Behaviour”. figshare. https://hdl.handle.net/2134/11499. 
This item was submitted to Loughborough's Institutional Repository (https://dspace.lboro.ac.uk/) by the author and is made available under the following Creative Commons Licence conditions.

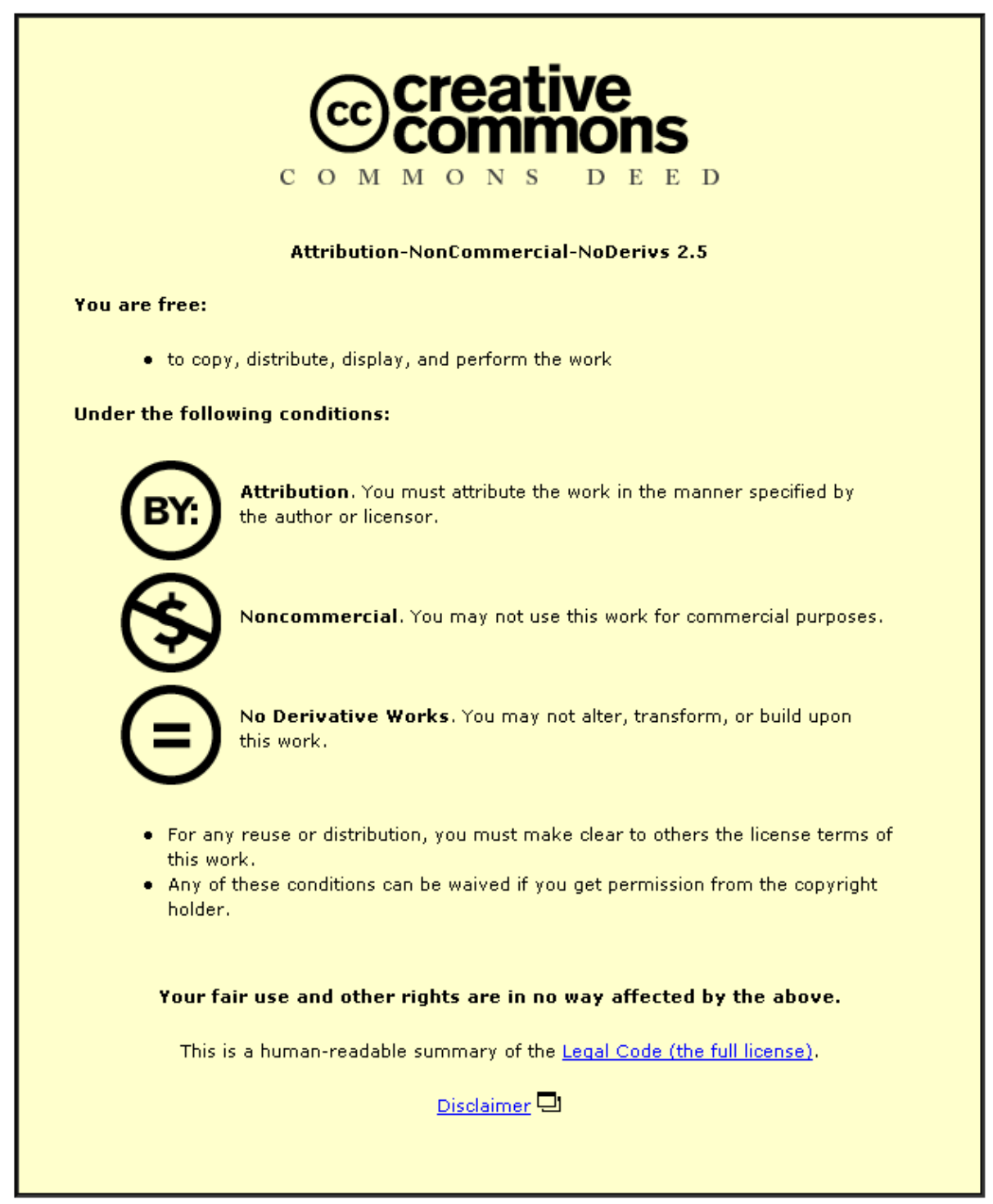

For the full text of this licence, please go to: http://creativecommons.org/licenses/by-nc-nd/2.5/ 


\title{
Attitudinal and socio-demographic effects on willingness to pay for water services and actual payment behaviour
}

\author{
Josses Mugabi $^{{ }^{*}}$ and Sam Kayaga ${ }^{\star *}$ \\ *The World Bank, 1818 H Street NW, Washington DC 20433, USA \\ ** Water, Engineering and Development Centre, Loughborough University, Leicestershire LE11 3TU, UK
}

\begin{abstract}
Improving revenue collection rates and minimising the levels of 'bad debts' is currently a top priority for managers of water utilities in low-income countries. This study used empirical data from a cross-sectional survey of 505 utility customers in eight urban centres in Uganda to show that customer attitude towards prompt payment, perceived ease or difficulty of paying on time (perceived control), as well as social pressure, strongly influence intentions to pay, which in turn directly affects actual prompt bill payment behaviour. The findings also show that gender, income, occupation of the household head and tenure status have statistically significant direct relationships with intentions, but their effects are much smaller compared to the joint influence of attitudes, perceived control and perceived social pressure. Moreover, the effects of gender and occupation are completely mediated by perceived control and social pressure respectively. These results have implications for improving revenue collection through customer-focused initiatives.
\end{abstract}

Key words: Willingness to pay; Water services; Developing countries

\footnotetext{
${ }^{1}$ Corresponding Author - email jmugabi@worldbank.org
} 


\section{Introduction}

Over a decade ago the 'Dublin Principles' ${ }^{2}$ shifted global thinking towards treating water as an economic good. Accompanying this conceptual shift has been a wider move towards focusing on water consumer's needs and preferences and their willingness to pay (WTP). WTP studies are now widely considered as forming part of an improved planning methodology for water supply, because they provide a basis for distinguishing financially viable water supply projects from those that are destined for failure. However, cost recovery is still a major problem even for those projects with seemingly good initial financial models. Consequently, the research community is now interested in providing a deeper understanding of the factors responsible for translating the consumer's self-reported WTP into actual payment behaviour (Kayaga et al, 2003; Kayaga et al, 2004; Addo-Yobo et al, 2006)

For water utilities, one of the key determinants of overall cost recovery efficiency is the ability to recover payment, within a reasonable timeframe, for all the water bills sent to customers. Delayed bill payments and huge arrears can greatly undermine a utility’s capacity to deliver water services. This is especially true for small water utilities in developing countries that depend on a constant stream of revenue from their customers in order to meet their operational costs. If a utility is not able to collect in time, all the bills that are sent out, cash flow problems set in, which in turn, impacts on the ability to cover operating expenses and extend service coverage. Such a situation may result in low service coverage, and potentially, poor customer service - leading to customer dissatisfaction, which may breed more 'non-payers' and trigger a cycle of poor performance. Thus, minimizing the levels of 'bad debts' and increasing the rates of revenue collection is critical for sustainable service provision.

\footnotetext{
${ }^{2}$ Dublin principles is short for the " United Nations Dublin Statement on Water and Sustainable Development, which was adopted by the United Nations on 31 January 1992 at the International Conference on Water and the Environment Dublin, Ireland, organized on 26-31 January 1992.
} 
In order to respond to problems involving delayed or irregular payments, utility managers need to determine precisely why customers might not pay their water bills in time. Yet, little empirical research exists in the literature on the factors influencing customer decisions when it comes to paying water bills in time. Although the body of knowledge on WTP for water services has grown tremendously since the early 1990s, most of this research has been conducted within hypothetical service settings, in which WTP for future service improvements is estimated. Limited research has been carried out on actual payment behaviour within an existing utility-customer relationship. Moreover, in most studies, attitudinal influences on WTP have not been fully examined, and there is virtually no research that has investigated whether other modifiable variables account for the relationship between socio-demographic factors and willingness to pay.

This article is aimed at filling these gaps. It extends the existing body of knowledge by examining the influence of attitudinal and socio-demographic factors on customer decisions relating to paying for water services promptly. The article is based on a wider research on bill payment behaviour in urban water utilities in Uganda, undertaken for a university academic qualification (Mugabi, 2007). The research questions addressed by this article are:

(i) What attitudinal and socio-demographic factors influence customer intentions to pay utility water bills promptly?

(ii) Do expressed intentions to pay water bills promptly translate into actual prompt bill payment behaviour?

(iii) Are socio-demographic effects on intentions to pay mediated by attitudinal factors? 


\section{Factors of affecting WTP for water services}

Understanding domestic water demand behaviour, especially in low-income countries, has attracted a considerable amount of research attention during the past two decades. In particular, there has been an upsurge of research looking at the determinants of household demand for water services and willingness to pay. The most influential research in this area was that sponsored by the World Bank between 1987 and 1990, and carried out by what came to be known as the World Bank Water Demand Research Team. Using mostly contingent valuation methods, the team conducted willingness to pay studies in several developing countries including Uganda (Whittington et al., 1998), Nigeria (Whittington et al., 1990), Philippines (Bohm et al., 1993), Pakistan (Altaf et al., 1993), India (Singh et al., 1993), Haiti (Whittington et al., 1990), Brazil (Briscoe et al., 1990), and Kenya (Mu et al., 1990).

Most of these studies were conducted in the context of rural water supply. Their common point of departure were two related questions: why households opt for an improved water service rather than their current supply and what determines how much they are willing to pay for the improved service. The World Bank Water Demand Research Team (1993) elegantly summarised the joint determinants of household willingness to use, or to pay for, improved water services into three sets of characteristics: (i) the socio-economic and demographic characteristics of the household, including gender, education and occupation of household head; (ii) the characteristics of the existing or traditional supply versus those of the improved water supply, including the cost, quality and reliability; and (iii) household attitudes towards government policy in the water supply sector and their sense of entitlement to government services.

Subsequent to the prolific work by the World Bank Water Demand Research Team, several researchers have adapted the methodology and conducted similar studies in different contexts (e.g. Perez-Pineda, 1999; Whittington et al., 2002; Hopkins et al., 2004; Gulyani et al., 2005; 
Casey et al., 2006; Pattanayak et al., 2006; Venkatachalam, 2006). The findings from this research generally confirm the set of WTP determinants revealed in earlier studies. For instance, Perez-Pineda’s (1999) study in four rural communities of El Salvador, Central America, showed that existing service characteristics, price of the improved service, together with a number of socio-economic features of respondents, are important determinants of willingness to pay. Similar findings are reported in studies conducted in four rural communities of Rwanda (Hopkins et al., 2004), the city of Manaus in Brazil (Casey et al., 2006), the town of Negombo in Sri Lanka (Pattanayak et al., 2006) and the peri-urban area of Mandapam in Coimbatore, India (Venkatachalam, 2006).

However, despite insights gained from the above studies, critical knowledge gaps still remain. A major weakness of the studies reviewed above is that they have focused mainly on demographic, socio-economic and service factors which are external influences on behaviour. Little or no attention has been paid to internal psychological factors such as beliefs, attitudes and societal factors that influence water demand and willingness to pay. Researchers in social psychology and behavioural sciences have long established that both internal and external factors play an important role in shaping any form of human behaviour (e.g., Ajzen and Fishbein, 1980; Ajzen, 1991; Ajzen and Fishbein, 2005). Yet, only a few studies have included internal factors such as attitudes in the determination of WTP.

A few of the studies carried out by the World Bank Water Demand Research Team (e.g. Whittington et al., 1990; Altaf et al., 1993; World Bank Water Demand Research Team, 1993) found that household's general attitudes towards government policy in the water supply sector and their sense of entitlement to free government services, significantly influenced their willingness to pay values. Similarly, studies conducted in the midst of reform proposals to involve the private sector in provision of services in the town of Negombo, Sri Lanka (Pattanayak et al., 2006) and in Kathmandu, Nepal (Whittington et al., 2002), showed that 
customer perceptions about private sector participation have an influence on willingness to pay.

These studies however have several methodological problems. Firstly, the authors confuse the attitude construct with related concepts of perceptions and values, thus introducing some question as to what was actually measured. Secondly, the authors elicit general attitudes towards specific targets (e.g. governments, service provider), but not attitudes towards a particular action (e.g. paying for the service). Studies have shown that attitude towards a target is not a reliable predictor of a specific behaviour (Ajzen and Fishbein, 1980; Meyerhoff, 2006). Thus, a positive attitude towards a water service provider does not mean that such an attitude will predict the actual behaviour of paying water bills. The reason for this is that a single behaviour is typically influenced by a broad variety of factors in addition to the attitude towards a target (Meyerhoff, 2006). Notwithstanding these methodological weaknesses, these studies show that where internal psychological influences exist, contingent valuation questions alone will fail to elicit the "true" economic value of improved water services to the household (World Bank Water Demand Research Team, 1993).

Another question about WTP research that remains largely unanswered in the literature is how socio-economic and demographic factors influence willingness to pay for water services. Micro-economic theory suggests that willingness to pay should vary across individuals with different socio-economic and demographic characteristics (Casey et al., 2006). But it does not explain why two individuals with similar socio-economic profile would have different willingness to pay levels. The World Bank Water Demand Research Team (1993) found that better-educated household members were willing to pay more for an improved water supply; that women were willing to pay more for better services than male respondents; and that respondents employed in the formal sector have better willingness to pay for improved services than those employed in informal sector. 
However, similar to many other WTP studies, the question of how these socio-demographic factors influence willingness to pay was not analysed. Instead, the authors offer what amounts to empirically unsupported hunches about explanations for the observed effects. For instance, on the effect of education, it is assumed that better-educated household members are more aware of the health and economic benefits of improved water supplies and are thus more likely to have a higher willingness to pay. On gender effects, it is assumed that because women in developing countries bear the burden of collecting water, they would attach more importance to improved water supplies than would men and therefore likely to have a higher willingness to pay. On the other hand, the World Bank Water Demand Research Team (1993) acknowledged that in most of their WTP studies, it was not clear how gender influences the respondents' indicated willingness to pay. Therefore, given that gender and other demographic variables are beyond the control of the utility, it is important that attempts are made to examine whether other modifiable variables account for the relationship between demographic variables and willingness to pay.

Finally, one of the most important questions about WTP research is the extent to which willingness to pay is translated into actual payment behaviour, and whether the factors influencing household decisions are constant over time or subject to change. In the extant literature reviewed, only one study by Griffin et al. (1995) has examined this question. Their “test-retest” type of contingent valuation (CV) study conducted ex-ante in 1988 and ex-post in 1991 in the Indian state of Kerala attempted to assess the extent to which willingness to pay for a house connection - which was assessed in 1988 - translated into actual behaviour (connection) following installation of the new piped water system three years later. Although a majority (91 percent) of households who said they would connect were actually found to have connected, the behavioural model estimated using the previous CV data did not predict behaviour quite as well as the simple descriptive statistics. This implies that household decisions in the ex-post situation were influenced by factors different from those in the $e x$ - 
ante situation. Moreover, of those households who said they would connect but had not connected, more than 75 percent reported inability to pay the connection cost as the major reason for their decision, while those who said they would not connect, but actually connected, cited "changed economic circumstances" as the major reasons for their decision (Griffin et al., 1995). These results suggest that the factors influencing an individual's willingness to pay are likely to be different from those influencing their actual behaviour.

In summary therefore, although the body of knowledge on WTP has grown tremendously since the early 1990s, most of the research has been conducted within hypothetical service settings, in which WTP for future service improvements is estimated. Limited research has been carried out on actual payment behaviour within an existing utility- customer relationship. Moreover, in most studies, attitudinal influences on WTP have not been fully examined, and there is virtually no research that has investigated whether other modifiable variables account for the relationship between socio-demographic factors and WTP.

\section{CONCEPTUAL FRAMEWORK}

Given the above inadequacies in the literature, it is worthwhile re-examining the influence of attitudinal and socio-demographic factors on decisions relating to paying for water, within the context of an existing utility-customer relationship. Whereas previous research has utilised econometric models for answers about who will, or will not, pay for improved water services, this research was guided by concepts in the behavioural sciences. The theoretical framework for the study was derived from Ajzen's $(1991 ; 2005)$ Theory of Planned Behaviour (TPB) one of the most widely used and successful socio-cognitive models for understanding human decision-making and behaviour.

The TPB proposes that the immediate determinant of behaviour is the individual's intention to perform, or not to perform that behaviour. Behavioural intentions are in turn, influenced by 
three factors: (i) the attitude towards the behaviour, which refers to the individual's favourable or unfavourable evaluation of performing the behaviour; (ii) the subjective norm, which is a social factor referring to the perceived social pressure to perform or not to perform the behaviour; and (iii) the degree of perceived control over the behaviour, which refers to the perceived ease or difficulty of performing the behaviour. To the extent that individuals hold positive attitudes toward the behaviour, think that there is normative support for performing the behaviour, and perceive that they can easily perform the behaviour, they should have strong intentions to perform the behaviour (Ajzen, 1991).

The TPB is an extension of the theory of reasoned action (TRA; Ajzen and Fishbein, 1980), which included only the first two determinants of intentions (i.e. attitude and subjective norms). Both models have been used extensively to understand and predict a wide range of human behaviours. In particular, the TPB has been used to predict health related behaviours such as condom use, smoking and exercise (e.g. Sheeran and Taylor, 1999); hygiene behaviours such as hand washing (e.g. Jenner et al., 2002), pro-environmental behaviours such as recycling (Cheung et. al, 1999), riparian zone management (Fielding et al., 2005), composting (Taylor and Todd, 1995), and water conservation (Lynne et al., 1995). The theory is especially applicable to behaviours that are not entirely under personal control, and it encompasses the relatively thoughtful process involved in considering personal costs and benefits of engaging in various kinds of behaviours (Petty et al., 1991).

This study utilised the TPB theoretical framework because the behaviour of 'paying water bills promptly' is not entirely under the control of the customer. It can be influenced by external factors such as irregular bill delivery (or non-billing), as well as personal factors such as lack of money and time. Figure 1 shows a schematic diagram of the research model as derived from the theory of planned behaviour. In this research model, prompt bill payment behaviour (PB) is defined as the action of paying an outstanding water bill at the utility office within 15 days of receiving the bill. 


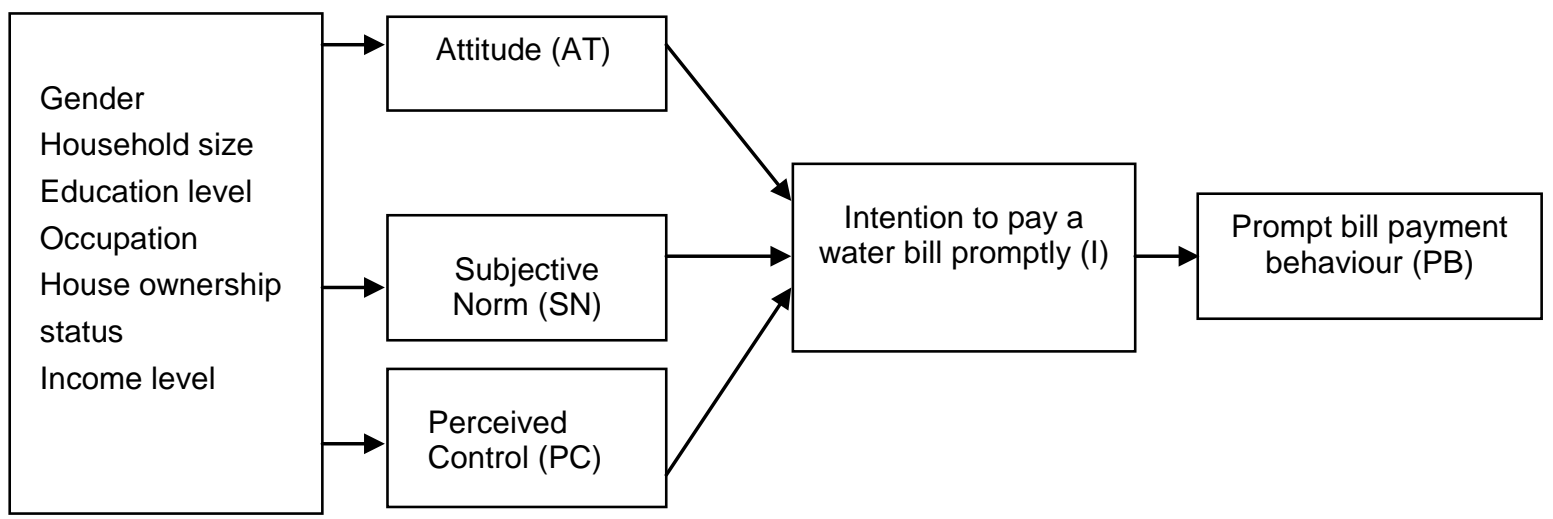

Fig 1: Research model based on the theory of planned behaviour

The use of the 15-day window is consistent with the service agreement terms used by the service providers in all the study towns. The intention to perform this behaviour herein referred to as intention to pay a water bill promptly (I) is defined as the perceived likelihood that a customer will pay his/her water bill within 15 days of receiving the bill. The three variables of attitude (AT), subjective norms (SN) and perceived control (PC) are predicted to have a positive direct influence on intentions, which in turn is expected to predict prompt bill payment behaviour, in line with the TPB theoretical framework (Ajzen, 1991).

Socio-demographic factors (such as gender, household size, education level of household head, occupation of household head, house ownership status, and income level)which have been treated in previous studies as direct determinants of willingness to pay are treated in this model as 'background factors'. In other words, they are predicted to influence intentions and behaviour indirectly by their effects on attitudes, subjective norms, and perceptions of control (Ajzen and Fishbein, 2005). Thus, consistent with Ajzen (1991) and Ajzen and Fishbein (2005), we do not expect significant direct effects of these household characteristics on intentions, after taking into account the effects of attitudes, subjective norms and perceived control. 
The main hypotheses emerging from the above conceptualisations can therefore be summarised as follows:

- The three variables of attitude, subjective norms and perceived control with respect to prompt bill payment will significantly predict, either individually or as part of a group of variables, some of the variation in a customer's intentions to pay a water bill promptly. Intentions will, in turn, significantly predict some of the variation in actual prompt bill payment behaviour.

- The effect of various socio-demographic factors (i.e. gender of household head; household size; education level of household head; occupation of household head; house ownership status; and income level) on intentions to pay a water bill promptly is mediated by the variables attitude, subjective norms and perceived control

The next section reports on the research design and methodology used in collecting relevant data for testing these relationships and answering the questions paused in section 1 above.

\section{METHODOLOGY}

Household data were collected from eight small urban centres (towns) in Uganda, with populations in the range of 5000 to 25000 inhabitants. The study towns were randomly selected from a sampling frame of 32 towns with piped water services. Water services in Uganda’s small urban centres are managed by local private operators under management contracts with the local government water authority. Services in larger urban centres are provided by National Water and Sewerage Corporation (NWSC), the national utility. The sampling frame did not include the larger towns served by NWSC.

The strategy of inquiry was a two-phase sequential approach. The first phase involved collection of qualitative data through focus group discussions in order to generate perception themes relating to the behaviour of paying water bills promptly. Then, based on these themes 
a quantitative measurement instrument (questionnaire) was developed and administered in the second phase through a cross-sectional survey of 631 registered domestic customers, which were randomly selected from the customer databases of the utilities involved. This instrument was used to obtain data on the key predictor variables as specified by the TPB theoretical framework. The process of developing the instrument proceeded as follows:

- A literature review was conducted to enable the development of operational definitions of the constructs, design the response scale format and generate questionnaire items.

- A draft questionnaire was produced based on the literature review and information obtained in the focus group discussions conducted in the first phase. Formatting guidelines suggested by Babbie (1990) and Bourque and Fielder (2003) were generally followed.

- The first draft of the questionnaire underwent a process of multiple pre-testing and piloting in line with social science research practice (Babbie, 1990; Neuman, 1994).

- On the basis of the pre-test and pilot study results, the questionnaire was further refined before it was ready to be administered.

As a result of this process, a questionnaire with Likert-type closed answers was developed. The questionnaire had 69 items in total. Intention was measured directly using a multi-item scale designed to capture overall intentions, as well as desires (e.g. 'I want to pay my next water bill within 15 days of receiving it') and self-predictions (e.g. 'how likely is it that you will pay your next water bill within 15 days of receiving it'). Attitude was measured directly using a semantic differential scale. The scale made use of bipolar adjectives that are evaluative in nature, such as good-bad, fair-unfair, harmful - beneficial (Ajzen, 2002b).

Subjective norms were measured directly using a combination of items that captured perceptions about what important others think the person should do, and perceptions about 
whether important “others” themselves actually perform the behaviour in question (Ajzen, 2002b). The referents groups/individuals identified in the focus group discussions included: neighbours; family members; and the water service provider (private operator). Finally, a direct measure of perceived control was obtained using items that captured: (i) people's confidence that they are capable of performing the behaviour; (ii) perceived difficulty of performing the behaviour or the likelihood that the participant could do it; and (iii) the degree of control a person has over performance of the behaviour, i.e. whether performance of the behaviour is or is not up to them (Ajzen, 2002a).

The process of questionnaire administration commenced on Thursday, $9^{\text {th }}$ February 2006 for most of the study towns, while for others, administration commenced on the weekend of $10^{\text {th }}$ February 2006. Two modes of administration were used: unsupervised self-administration for respondents who were literate and who claimed they understood all contents of the questionnaire; and supervised face-to-face administration by trained interviewers for respondents who were illiterate and/or who claimed they did not understand some /all of the contents of the questionnaire. Use of two methods of questionnaire administration raised the response rate considerably. Out of a net sample size of 505 questionnaires that were actually delivered 490 usable questionnaires were returned, giving a response rate of 97 percent.

Finally, data for prompt bill payment behaviour (PB), the main dependent variable, was obtained using a specially designed monitoring form. The form was designed to monitor customer response to the water bill for the end of February 2006 following questionnaire administration. The objective was to obtain the proportion of total debt paid within the 15day window. Only those customers who had responded to the questionnaire were monitored. However, out of a total 490 respondents who participated in the survey, 41 entries for prompt bill payment behaviour were either incomplete or suspected to be erroneous and were omitted altogether. 


\section{EMPIRICAL RESULTS}

\subsection{Classification data}

Slightly more males (51.5 percent) than females (48.5 percent) completed the questionnaire. Over half (52 percent) of the sampled households had 6 to10 people and house premises were predominantly privately owned (79 percent). Most of the respondents reported to have had a formal education level of at least seven years (86 percent), and more were self-employed in business and professional sector (43 percent), compared to 32 percent in formal employment. A sizeable number (25 percent) were without formal employment. Comparisons with the Uganda Bureau of Statistics $(2001 ; 2003)$ population and housing data indicated that the sample was similar in many ways to the population from which it was drawn.

\subsection{Psychometric tests}

In accordance with Ajzen's (2002b) recommendation, measures of the four main independent variables (i.e. attitude, subjective norm, perceived control and intention) were checked for acceptable psychometric qualities - i.e. internal consistency reliability and validity. Internal consistency reliability was assessed using Cronbach’s coefficient alpha (Pedhazur and Schmelkin, 1991), the results of which are shown in Table 1. The results displayed in Table 1 show that each scale had acceptable to good internal reliability (Kline, 1999; Francis et al., 2004).

Table 1: Reliability analysis for attitude, subjective norm, perceived control and intention scales

\begin{tabular}{lcccc}
\hline Scale & Valid cases (N) & Final scale items & Cronbach's alpha & $\begin{array}{c}\text { Item-to-total correlations } \\
\text { (range) }\end{array}$ \\
\hline Attitude & 485 & 6 & .84 & $.45-.72$ \\
$\begin{array}{l}\text { Subjective } \\
\text { norm }\end{array}$ & 483 & 4 & .65 & $.38-.49$ \\
$\begin{array}{l}\text { Perceived } \\
\text { control }\end{array}$ & 482 & 5 & .79 & $.39-.67$ \\
\begin{tabular}{l} 
Intention \\
\hline
\end{tabular} & 478 & 5 & .77 & $.43-.65$ \\
\hline
\end{tabular}


Construct validity was established through exploratory factor analysis. The objective was to define the internal structure of the set of items and assess whether they measured what they were intended to measure (Pett et al., 2003). Using the principal-component method, the scales were factor analysed, and the resultant factor matrices subjected to orthogonal rotation (varimax method) in order to produce simple interpretable structures (Pedhazur and Schmelkin, 1991; Nunnally and Bernstein, 1994; Tabachnick and Fidell, 2001).

Consequently, factor analysis of items intended to measure attitude, subjective norm and perceived control yielded a three factor structure that explained more than 50 percent of the variance, implying good scale validity (Pedhazur and Schmelkin, 1991). Similarly, all items on the intention scale clustered onto one factor accounting for 54 percent of the total variance in intention items, thus providing evidence of scale validity.

\subsection{Regression analyses}

Regression analyses were carried out to examine the relative importance and explanatory power of the predictors of intentions and behaviour. Two separate sets of analyses were performed. The first analysis utilised linear regression techniques with ordinary least squares (OLS) estimation to examine the relative importance and explanatory power of the three hypothesised predictors of intention to pay a water bill promptly (I), that is, attitude toward the behaviour (AT), subjective norms (SN) and perceived control (PC). The linear regression model was specified as follows:

$$
\mathrm{I}=\alpha+\beta_{1} \mathrm{AT}+\beta_{2} \mathrm{SN}+\beta_{3} \mathrm{PC}+\varepsilon
$$

where I is intention to pay water bill promptly; AT is attitude towards paying water bill promptly; $\mathrm{SN}$ is subjective norm; $\mathrm{PC}$ is perceived control; $\alpha$ is the regression constant and $\varepsilon$ is the residual term. 
The null hypothesis $\left(\mathrm{H}_{0}\right)$ tested for the above model is $\mathrm{H}_{0}: \beta_{1}=\beta_{2}=\beta_{3}=0$, where $\beta_{1}, \beta_{2}, \beta_{3}$ are the standardised regression coefficients. The alternative hypothesis for the model is that at least one of the regression coefficients is not equal to zero. The results of the linear regression analysis are summarised in Table 2.

Table 2: Summary of results for linear regression analysis with "intention" as the outcome variable and attitude, subjective norm and perceived control as the predictors

\begin{tabular}{|c|c|c|c|c|c|c|c|}
\hline \multirow[t]{2}{*}{ Model } & \multirow[t]{2}{*}{$\begin{array}{l}\text { Unstandardised } \\
\text { coefficients }\end{array}$} & \multirow[t]{2}{*}{$\begin{array}{l}\text { Standard } \\
\text { error }\end{array}$} & \multirow{2}{*}{$\begin{array}{l}\text { Standardised } \\
\text { coefficients }(\beta)\end{array}$} & \multirow[t]{2}{*}{$\mathrm{t}$ - ratio } & \multicolumn{2}{|c|}{$\begin{array}{c}\text { 95\% CI for } \\
\text { beta coefficients }\end{array}$} & \multirow{2}{*}{$\begin{array}{c}\text { Semi- } \\
\text { partial } \\
\text { correlations }\end{array}$} \\
\hline & & & & & Lower & Upper & \\
\hline Constant & 0.16 & 0.16 & & & & & \\
\hline Attitude & 0.29 & 0.04 & 0.24 & $7.04^{* * *}$ & 0.21 & 0.37 & .208 \\
\hline Subjective norm & 0.15 & 0.03 & 0.16 & $4.81^{* * *}$ & 0.09 & 0.22 & .142 \\
\hline $\begin{array}{l}\text { Perceived } \\
\text { control }\end{array}$ & 0.52 & 0.03 & 0.55 & $15.52 * * *$ & 0.46 & .59 & .458 \\
\hline
\end{tabular}

Model summary: $\mathrm{R}^{2}=.611 ;$ adjusted $\mathrm{R}^{2}=.609 ; \mathrm{F}=234.29^{* * *} ; \mathrm{N}=451 \quad * * * *$ Significant at $\mathrm{p}<.001$

The results displayed in Table 2 show that all the three predictor variables of attitude ( $\mathrm{t}(447)$ $=7.04, \mathrm{p}<.001)$, subjective norms $(\mathrm{t}(447)=4.81, \mathrm{p}<.001)$ and perceived control $(\mathrm{t}(447)=$ 15.52, $\mathrm{p}<.001$ ) are very highly significantly related to intentions, and hence the null hypothesis that $H_{0}: \beta_{1}=\beta_{2}=\beta_{3}=0$ is rejected at $\mathrm{p}<.001$. Subjective norm has the smallest Beta coefficient $\left(\beta_{2}=.163, t=4.8\right)$, and perceived control has the largest $\left(\beta_{3}=.550, t=15.52\right)$, implying that subjective norm is the least important and perceived control the most important predictor. The 95\% confidence intervals for the Beta coefficients are relatively tight, indicating that the coefficient estimates for this model are likely to be representative of the true population (Field, 2005). All three predictors jointly account for a large percentage (61 percent $)$ of the variation in intentions $\left(\mathrm{R}^{2}=.61\right)$ and the $\mathrm{F}$-ratio $(\mathrm{F}=234.29, \mathrm{p}<.001)$ is very highly significant, suggesting that there is a relationship between the predictor variables and the outcome variable that cannot be attributed to chance. Furthermore, the difference between 
the value of $\mathrm{R}^{2}$ and the adjusted $\mathrm{R}^{2}$ is very small (.002), implying that the cross-validity of this model is very good (Field, 2005).

To check whether the model fits the data well, outliers and influential cases were examined using an elaborate procedure suggested by Field (2005). There was no evidence of influential cases within the data, hence suggesting a fairly accurate model. Moreover, tests for the assumptions of linear regression revealed no violations, suggesting that these results can be used to make inferences beyond the sample of data collected.

The second set of analyses utilised logistic regression techniques to examine the extent to which intentions are predictive of actual behaviour. This analytical technique was deemed the most appropriate because of the nature of the outcome variable. Data for prompt bill payment behaviour data exhibited little variation between the zero and 100 percent limits. This means that using linear regression techniques would have almost certainly led to a poor model because the assumption of normally distributed residuals is difficult to sustain with a skewed outcome variable (Miles and Shevlin, 2001; Field, 2005).

Therefore, consistent with this analytical technique, prompt bill payment behaviour - the outcome variable - was transformed into a dichotomous variable, categorising the data into those customers who fully paid their water bill within the 15-day window (58 cases) and those who did not pay (243 cases). The logistic regression model is concerned with predicting the probability that a customer belongs to the category of those who fully paid their water bill within the 15-day window, given their score on the intention variable. This model is specified as follows:

$$
P(\text { paid fully })=\frac{1}{1+\mathrm{e}^{-\left(\alpha+\beta_{1} \mathbf{I}+\varepsilon\right)}}
$$


where: $\mathrm{P}$ (paid fully) - is the probability that a customer belongs to the category of those who fully paid their water bill within the 15-day window; I is intention to pay water bill promptly; e is the base of natural logarithms; $\varepsilon$ and $\alpha$ are the error and constant terms respectively

The null hypothesis $\left(\mathrm{H}_{0}\right)$ tested is $\mathrm{H}_{0}$ : $\beta_{1}=0$, where $\beta_{1}$ is the logistic regression coefficient. The alternative hypothesis is that $\beta_{1}$ is not equal to zero. Estimation results for the logistic regression model are presented in Table 3.

From Table 3, the model chi-square $\chi^{2}(1)=7.85,(\mathrm{p}=.005)$ is statistically significant at $\mathrm{p}<.05$, implying that it is unlikely that chance effects alone would predict the outcome variable as well as the model. Furthermore, the coefficient estimate for intentions is statistically significant $(\mathrm{p}<.05)$ implying that intention makes a statistically significant contribution to the prediction of prompt bill payment behaviour.

Table 3: Summary of logistic regression results

\begin{tabular}{|c|c|c|c|c|c|c|c|}
\hline \multirow[t]{2}{*}{ Model } & \multirow[t]{2}{*}{ Model $\chi^{2}$ (p-value) } & & \multicolumn{2}{|c|}{$\begin{array}{l}\text { Logistic regression } \\
\text { coefficients }\end{array}$} & \multicolumn{3}{|c|}{$95 \% \mathrm{CI}$ for $\exp \beta$} \\
\hline & & & $\beta$ & $\begin{array}{l}\text { Standard } \\
\text { error }\end{array}$ & Lower & $\exp \beta$ & upper \\
\hline \multirow[b]{2}{*}{ P(Paid fully) } & \multirow[b]{2}{*}{$7.85^{* *}(\mathrm{p}=.005)$} & Constant & -4.70 & 1.10 & & & \\
\hline & & Intention & $0.72 *$ & 0.27 & 1.22 & 2.06 & 3.48 \\
\hline
\end{tabular}

Hosmer and Lemeshow $\chi^{2}=8.52^{\mathrm{ns}}(\mathrm{p}=.38)$;

** Significant at $\mathrm{p}<.01 ; \quad *$ significant at $\mathrm{p}<.05 ;$ ns - not significant at $\mathrm{p}<.05$

To further test the explanatory power of the model, the Hosmer and Lemeshow (H-L) goodness-of-fit test (Hosmer and Lemeshow, 2000) was applied. This test compares the amount of information gained by constructing the model to the amount of information available without the model (the null case). Thus, a non-significant test would indicate a model that does not differ significantly from the observed data. The H-L goodness-of-fit test 
statistic was non significant at $\mathrm{p}<.05$, implying that estimates from the model fit the data to an acceptable level (Field, 2005).

\subsection{Tests for mediator effects}

A number of socio-demographic characteristics were hypothesised to influence intentions through their effects on attitude, subjective norms and perceived control (Figure 1). These effects were tested using the mediator regression analysis framework advanced by Baron and Kenny (1986), and used extensively in process analysis (Kenny, 2006). This analytical procedure consists of four steps that must be taken to establish that a mediated relationship exists. For example, consider three variables, $\mathrm{X}$, the predictor variable, $\mathrm{Y}$, the outcome variable and $\mathrm{M}$, the mediator variable. In order to establish that variable $\mathrm{M}$ mediates the relationship between $\mathrm{X}$ and $\mathrm{Y}$, the following conditions must be satisfied (Baron and Kenny, 1986; Kenny, 2006):

1. Show that $\mathrm{X}$ is a significant predictor of $\mathrm{Y}$, thus establishing that there is an effect that may be mediated;

2. Show that $\mathrm{X}$ is a significant predictor of $\mathrm{M}$;

3. Show that $\mathrm{M}$ is a significant predictor of $\mathrm{Y}$, when controlling for $\mathrm{X}$; and

4. If $\mathrm{M}$ is a complete mediator of the relationship between $\mathrm{X}$ and $\mathrm{Y}$, the effect of $\mathrm{X}$, when controlling for $\mathrm{M}$, should be zero.

Therefore, to establish whether attitudes, subjective norms and perceived control mediate the relationship between socio-demographic characteristics and intentions, we started by finding out whether a relationship exist that may be mediated. For each household characteristic, a linear regression analysis was performed; with the household variable as the predictor and intention as the outcome. All household variables, except household size, were measured on categorical level, and so dummy variables were created for use in the regression models. 
Table 4 shows a summary of the results showing $\mathrm{R}^{2}$ values, F-statistics and their significance for each household characteristic. From the results displayed in Table 4, it can be noted that the only household characteristics related to intentions are gender of the household head $(\mathrm{F}=$ 7.89, $\mathrm{p}=.005)$, occupation of the household head $(\mathrm{F}=2.19, \mathrm{p}=.05)$, house ownership status $(\mathrm{F}=4.87, \mathrm{p}=.002)$, and income level of the household head $(\mathrm{F}=3.45, \mathrm{p}=.002)$. Household size and education level of the household head did not have a statistically significant influence on intention, and were therefore dropped at this stage of the analysis.

Table 4: Summary of results of linear regression analysis with household variables as the predictors and intention as the outcome variable

\begin{tabular}{lccc}
\hline Household variable (predictors) & Valid cases $(\mathrm{N})$ & $\mathrm{R}^{2}$ values & F- statistic \\
\hline Gender & 475 & .02 & $7.89^{* *}$ \\
Household size & 449 & .01 & $2.67^{\mathrm{ns}}$ \\
Education (number of years spent in formal education) & 477 & .004 & $0.71^{\mathrm{ns}}$ \\
Occupation type & 479 & .02 & $2.19^{*}$ \\
House ownership status & 477 & .03 & $4.87^{* *}$ \\
Monthly income & 480 & .04 & $3.45^{* *}$ \\
\hline
\end{tabular}

** Significant at $\mathrm{p}<.01$; * significant at $\mathrm{p}<.05$ ns - not significant at $\mathrm{p}<.05$

Source: Survey data

The next step was to ascertain whether gender, occupation, house ownership and income were correlated with attitude, subjective norms, and perceived control. For each of these household characteristics, three separate regression analyses were performed with attitude, subjective norms and perceived control as the outcome variables. The results of this analysis are shown in Table 5. None of the household variables were significantly related to attitude, implying that attitude was unlikely to mediate their effects on intentions. Also, occupation of the household head was the only household variable with a statistically significant relationship with subjective norms $(\mathrm{F}=2.74, \mathrm{p}=.02)$, implying that subjective norm was likely to act as a mediator of the relationship between occupation and intentions, but not for the other household variables. Gender of the household head had a statistically significant relationship 
with perceived control $(\mathrm{F}=3.98, \mathrm{p}=.047)$, but all other household variables did not show a relationship. The results of this step therefore suggest that while gender, occupation, house ownership and income have statistically significant direct relationships with intentions, only the effects of gender and occupation are likely to be mediated by TPB variables.

Table 5: Summary of results of linear regression analyses with household variables as the predictors and AT, SN and PC as the outcome variables

\begin{tabular}{lcccc}
\hline $\begin{array}{l}\text { Household characteristics } \\
\text { (predictor variables) }\end{array}$ & Outcome variables & Valid cases (N) & $\mathrm{R}^{2}$ values & F- statistic \\
\hline Gender & AT & 475 & .001 & $0.55^{\text {ns }}$ \\
& SN & 483 & .002 & $1.18^{\text {ns }}$ \\
& PC & 477 & .01 & $3.98^{*}$ \\
\hline Occupation type & AT & 479 & .02 & $1.56^{\text {ns }}$ \\
& SN & 487 & .03 & $2.74^{*}$ \\
& PC & 481 & .02 & $1.70^{\text {ns }}$ \\
\hline House ownership status & AT & 477 & .01 & $0.84^{\text {ns }}$ \\
& SN & 485 & .01 & $1.21^{\text {ns }}$ \\
& PC & 479 & .01 & $2.10^{\text {ns }}$ \\
\hline Monthly income & AT & 480 & .02 & $1.49^{\text {ns }}$ \\
& SN & 488 & .02 & $1.91^{\text {ns }}$ \\
& PC & 482 & .02 & $1.72^{\text {ns }}$ \\
\hline
\end{tabular}

* Significant at $\mathrm{p}<.05$ ns - not significant at $\mathrm{p}<.05$

Source: Survey data

Therefore, in order to test for mediation effects, the following regression equations are estimated in line with the third and four steps of the mediator regression analysis framework (Baron and Kenny, 1986; Kenny, 2006):

$$
\begin{aligned}
& \mathrm{I}=\alpha_{1}+\beta_{1} \mathrm{OCCd}_{1}+\beta_{2} \mathrm{OCCd}_{2}+\beta_{3} \mathrm{OCCd}_{3}+\beta_{4} \mathrm{OCCd}_{4}+\beta_{5} \mathrm{OCCd}_{5}+\beta_{6} \mathrm{SN} \\
& \mathrm{I}=\alpha_{2}+\beta_{7} \mathrm{GENd}_{1}+\beta_{8} \text { PC }
\end{aligned}
$$

Where: I is intention

$\mathrm{OCCd}_{\mathrm{i}}$ are dummy variables for household variable OCCUPATION 
$\mathrm{SN}$ is subjective norm

$\mathrm{GENd}_{1}$ is the dummy variable for GENDER

PC is perceived control

The results for the above regression models are summarised in Tables 6 and 7. The results displayed in Table 6 show that subjective norm is a statistically significant $\left(\beta_{6}=0.51, \mathrm{t}\right.$ $=12.69, \mathrm{p}<.001$ ) predictor of intention even after controlling for the effects of occupation. This satisfies the third condition of the mediator regression analysis framework. Table 6 also shows that the standardised beta coefficients for all the occupation dummy variables are non significant (at $\mathrm{p}<.05$ ), implying that they are not significantly different from zero.

Table 6: Summary of results for multiple regression analysis testing for the mediating effect of subjective norms on the relationship between occupation of household head and intention to pay water bills promptly

\begin{tabular}{llcccc}
\hline $\begin{array}{l}\text { Outcome } \\
\text { variable }\end{array}$ & $\begin{array}{l}\text { Predictor } \\
\text { variables }\end{array}$ & $\begin{array}{l}\text { Unstandardised } \\
\text { coefficients }\end{array}$ & Standard error & $\begin{array}{c}\text { Standardised } \\
\text { coefficients }(\beta)\end{array}$ & $\mathrm{t}$ - ratio \\
\hline Intention (I) & $\mathrm{SN}$ & 0.50 & 0.04 & 0.51 & $12.70^{* * *}$ \\
& OCC $_{\mathrm{d} 1}$ & -0.04 & 0.12 & -0.02 & $-0.37^{\mathrm{ns}}$ \\
& OCC $_{\mathrm{d} 2}$ & -0.09 & 0.08 & -0.05 & $-1.16^{\mathrm{ns}}$ \\
& OCC $_{\mathrm{d} 3}$ & 0.13 & 0.10 & 0.05 & $1.29^{\text {ns }}$ \\
& OCC $_{\mathrm{d} 4}$ & -0.11 & 0.06 & -0.01 & $-0.19^{\text {ns }}$ \\
& OCC $_{\mathrm{d} 5}$ & -0.09 & 0.07 & 0.05 & $-1.26^{\text {ns }}$ \\
\hline
\end{tabular}

Model summary: $\mathrm{R}^{2}=.28$; adjusted $\mathrm{R}^{2}=.27 ; \mathrm{F}=29.26^{* * * *}$;

**** Significant at $\mathrm{p}<.001 \mathrm{~ns}-$ not significant at $\mathrm{p}<.05$

Source: Survey data

This result provides evidence that the effects of occupation on intentions are completely mediated by subjective norms - i.e. people with different occupations had different behavioural intention strengths because of differences in their perceptions of social pressure to perform the behaviour. Similarly, the results in Table 7 show that perceived control is a very highly statistically significant $\left(\beta_{8}=0.73, \mathrm{t}=22.79, \mathrm{p}<.001\right)$ predictor of intentions when we control for the effects of gender. The standardised beta coefficient for the gender dummy variable is non significant $\left(\beta_{7}=-0.05, \mathrm{t}=-1.55, \mathrm{p}=.12\right)$, indicating that the effect of gender on intentions is not significantly different from zero when perceived control is controlled. 
This result therefore suggests that the effects of gender on intentions are completely mediated by perceived control. In other words, males and females differ in the strength of their intentions to pay water bills promptly because of differences in their perception of control over the behaviour.

Table 7: Summary of results for multiple regression analysis testing for the mediating effect of perceived control on the relationship between gender of household head and intention to pay water bills promptly

\begin{tabular}{lccccc}
\hline $\begin{array}{l}\text { Outcome } \\
\text { variable }\end{array}$ & $\begin{array}{l}\text { Predictor } \\
\text { variables }\end{array}$ & $\begin{array}{l}\text { Unstandardised } \\
\text { coefficients }\end{array}$ & Standard error & $\begin{array}{c}\text { Standardised } \\
\text { coefficients } \\
(\beta)\end{array}$ & $\mathrm{t}-$ ratio \\
\hline Intentions & PC & 0.69 & 0.03 & 0.73 & $22.79^{* * *}$ \\
& GEN $_{\mathrm{d} 1}$ & -0.06 & 0.04 & -0.05 & $1.55^{\mathrm{ns}}$ \\
\hline
\end{tabular}

Model summary: $\mathrm{R}^{2}=.54$; adjusted $\mathrm{R}^{2}=.53 ; \mathrm{F}=266.85^{* * *}$;

$* * * *$ Significant at $\mathrm{p}<.001$ ns - not significant at $\mathrm{p}<.05$

Source: Survey data

\section{DISCUSSION}

\subsection{Attitudinal effects on intentions to pay water bills promptly}

The results displayed in Table 2 indicate that the three variables - attitude, subjective norm and perceived control - jointly account for a large percentage (61 percent) of the variation in intentions, with a very highly significant overall fit to the regression model $(F=234.29$, $\mathrm{p}<.001)$. Furthermore, examination of the regression coefficients reveals that all three predictor variables make a statistically significant individual contribution to the prediction of intention. The semi-partial correlation coefficients reveal that perceived control explains 21 percent of the variance in intentions when the effect of the other two variables is controlled. The attitude variable uniquely explains 4 percent while subjective norms alone explain only 2 percent of the variance in intention. This result suggests that when it comes to paying a water bill promptly, customer perceptions of the ease or difficulty of engaging in the behaviour are 
far more important in determining their decisions than attitude towards the behaviour or their perception of social pressure.

Further statistical analysis outside the scope of this article showed that perceptions of control were a reflection of a number of perceived barriers to prompt payment, which included: (i) high water bills (Mugabi, 2007): (ii) frequent service interruptions; (iii) mistakes in meter readings, (iv) increase in water consumption, (v) unanticipated circumstances that place extra demands on household budget; (vi) coloured or unclear water; and (vii) financial difficulties. With the exception of unanticipated circumstances and financial difficulties, the rest of the factors perceived to impede prompt bill payment, relate to service delivery issues that are within the full control of a water utility. This observation suggests that opportunities exist for water utilities to motivate customer decisions about prompt payment of water bills.

\subsection{Socio-demographic effects on intentions to pay water bills promptly}

The results displayed in Tables 4 through to 7 indicate that four out of the six sociodemographic variables have statistically significant positive effects on intention. These four variables are: gender $(F=7.89, \mathrm{p}=.005)$, occupation $(\mathrm{F}=2.19, \mathrm{p}=.05)$, income level of the household head $(\mathrm{F}=3.45, \mathrm{p}=.002)$, and house ownership status $(\mathrm{F}=4.87, \mathrm{p}=.002)$.

However, from the magnitude of $\mathrm{R}^{2}$ values given in Table 4, it is clear that the effect of these socio-demographic variables on intention to pay water bills promptly is much smaller compared to the joint influence of attitudinal variables. Moreover, the effects of gender and occupation are completely mediated by perceived control and subjective norms respectively.

House ownership status and income level maintain independent effects on intentions which cannot be explained by any of the attitudinal variables. Customers staying in houses that they privately own, have strong intentions to pay their bills than those staying in rented or government owned houses. The effects appear to stem from the fact that customers who stay in rented or government owned premises do not necessarily enter into an agreement with 
water utility as is the case with house owners. As a result, renters and those staying in government houses are likely to be reluctant with paying water bills as they have no obligation to the water utility which has an agreement with the landlord.

Regarding gender influences, the results show that men have stronger intentions to pay their water bills promptly compared to women. This result contradicts what is usually reported in CV studies that women are more willing to pay for improved water services than men. The reason most commonly cited to explain the higher WTP exhibited by women is that because women carry the responsibility for basic household necessities that require water (such as food preparation and food hygiene), they are more willing to pay for water provision. The current study shows that this reasoning may not be valid when it comes to the actual behaviour of paying for water.

The results show that gender effects on intentions are mediated by the perceived control variable. In other words, males and females differ in the strength of their intentions to pay water bills promptly because of differences in their perception of control over the behaviour. Female-headed households perceive less control over paying water bills in time than maleheaded households. This difference could be due to a number of reasons. First, it is likely that some of the perceived barriers to prompt payment (e.g. service interruptions) are held more strongly among women than men. Secondly, in the current context, there is evidence to suggest that female-headed households are more likely to experience financial difficulties than their male counterparts. According to a recent Uganda National Household Survey, more men (61 percent) are engaged in paid employment compared to women (Uganda Bureau of Statistics, 2003). Household heads engaged in paid employment receive a steady income, which may increase the resources and opportunities available to them in the behavioural context. 


\section{RESEARCH IMPLICATIONS}

\subsection{Implications for water utility manager}

The findings of this research have practical implications for improving revenue collection through customer-focused initiatives. In particular, opportunities exist for water utilities to motivate customer decisions about prompt payment of water bills by influencing their attitudes towards the behaviour, perception of social pressure and control. Moreover, the results of the regression analysis showed that when it comes to paying a water bill promptly, customer perceptions of control (i.e. the ease or difficulty of engaging in the behaviour) are far more important in determining their decisions than attitude towards the behaviour or their perception of social pressure.

Therefore, utility managers need to put in place systems and processes to reduced barriers to prompt bill payment. Needless to say, a key area of concern is the billing systems. Managers need to minimise errors and mistakes in billing, as well as reducing wastage and losses incurred through tap leakages and faulty meters. Findings from focus group discussions reported elsewhere (Mugabi et al, 2007) revealed that customers often receive high water bills that reflect malfunctioning installations (such as taps and meters) due to infrequent or poor maintenance. In most cases, leakage and wastage is reported as the primary cause of high water bills, leading to non-payment. Understandably, customers would be unwilling to pay for water they did not consume, and therefore, utilities need to be proactive. Initiatives could include more frequent meter readings, increasing customer awareness, facilitating checks and repairs and carrying out demand management and water conservation programs.

Furthermore, given the low disposable incomes of customers in developing countries, utilities need to design flexible billing and payment arrangements to help customers pay their bills when they have the money on hand rather than on a monthly basis, as is the case in most countries. Utilities may also need to explore incentive mechanisms in the form of discounts 
or vouchers for prompt and regular payment. Such mechanisms serve to demonstrate to customers that the utility strongly desires to receive payments in time, thereby increasing the normative pressure on customers to respond quickly to bills.

In addition to making changes in the billing systems, utilities can develop publicity and educational messages aimed at bringing about desirable changes in customer attitudes, subjective norms and perceptions of control with respect to paying water bills promptly. Such publicity messages however must be informed by an in-depth understanding of the beliefs and perceptions that inform attitudes, subjective norms and perceived control. Utilities can gain this understanding using focus group discussions with customers (Mugabi et al, 2007).

Finally, in terms of designing behavioural change strategies, socio-demographic issues are beyond the control of the water utility. However, knowing how customers with different socio-demographic profiles respond to water bills provides a basis for developing and targeting remedial actions. For instance, water utility managers should take advantage of the higher intention to pay exhibited by men, by making it easier for them to translate their intentions into actual behaviour, through a combination of measures including better billing, targeted publicity messages and better service. Given the finding that women and men differ in the strength of their intentions to pay because of differences in perceived control, special initiatives such as flexible billing and payment are likely to have higher impact if they are targeted and promoted to female-headed households. The findings also highlight the consequences of lack of contractual responsibilities for tenants, as regards water services. Water utility managers should devise means of creating legal contracts (or service agreements) directly with consumers, so they are liable for bills sent on account of water services supplied to them, other than creating contracts with only the landlords.

\subsection{Implications for theory}


Apart from the practical implications discussed above, the findings of this research also have important implications for the wider body of knowledge on WTP for water services. Previous research has relied more on econometric models for answers about who will, or will not pay for improved water services. This approach predicts behaviour using external factors such as income, price and other socio-demographic variables, but fails to account for internal psychological factors. Moreover, selecting suitable socio-demographic factors for inclusion in prediction models is problematic due to the presence of a multitude of such factors, and studies to date have produced conflicting results of the relevance of different factors.

In contrast, the socio-cognitive perspective adopted in this research focuses on the process by which consumers make decisions. At the heart of this approach is the attitude concept, which for the past three decades, has remained central to the various theories developed by social psychologists for the purpose of understanding and predicting human behaviour. The most influential theories have been those guided by the reasoned action approach, in particular the theory of planned behaviour (TPB).

This study showed that socio-cognitive theories offer an alternative and complementary theoretical framework for understanding variations in WTP. The TPB can address the question of why two people with similar socio-demographic profiles would have different WTP. Basic economic theory on the other hand, is capable of explaining why two people with similar behavioural profiles might still have different WTP and behaviours.

Thus, econometric and socio-cognitive perspectives represent different but complementary view points for examining customer decisions relating to WTP for water services. The sociocognitive perspective focuses on factors internal to the individual, while econometric models focus largely on external factors. As such, relying on only one perspective ignores a set of potentially valuable explanatory variables. Future research on WTP should consider ways of 
combining elements from both perspectives, with survey instruments designed to elicit both behavioural and econometric information. Such integration of econometric models with the socio-cognitive models offers a basis for future research in this direction.

\section{CONCLUSION}

This paper has examined the influence of attitudinal and socio-demographic factors on customer decisions relating to paying for water services promptly. Using empirical data from Uganda, the paper has provided evidence in support of the theory of planned behaviour, that customer attitude towards prompt payment, perceived ease or difficulty of paying on time (perceived control), as well as social pressure, strongly influence intentions to pay, which in turn directly affects actual prompt bill payment behaviour.

Thus, it follows that attitudes, perceptions of social pressure and control are important factors for motivating customer decisions about paying for water services promptly. However, perceptions of control -which reflect both internal and external impediments and obstacles are far more important than attitude or the perception of social pressure. The paper also showed that gender, income level, occupation of the head of household and house tenure status have statistically significant direct relationships with intentions to pay, but their effects are much smaller compared to the joint influence of attitudes, perceived control and perceived social pressure. Moreover, the effects of gender and occupation can be explained by perceived control and social pressure respectively.

In summary, this research made three major contributions. Firstly, the application of a sociocognitive theoretical perspective to understand domestic water demand behaviour has complemented the economic perspective that is dominant in the water sector. Secondly, this is the first reported study to examine the influence of both attitudinal and socio-demographic factors on customer decisions to pay for water, and whether the effect of socio-demographic variables on intentions to pay can be explained by attitudinal variables. Thirdly, the research 
extends knowledge that supports the utility of the theory of planned behaviour as a useful conceptual framework for understanding consumer decision-making and behaviour in the urban water supply sector.

\section{REFERENCES}

Addo-Yobo, F. N., Njiru, C. and Sohail, M. (2006). "Determinants of household's intention to pay for improved water services: an application of the Theory of Reasoned Action." Journal of Water Supply: Research and Technology-AQUA 55(6): pp 419-425.

Ajzen, I. (1991). "The Theory of Planned Behaviour." Organisational Behaviour and Human Decision Processes 50(1991): 179-211.

Ajzen, I. (2002a). "Perceived behavioural control, self-efficacy, locus of control, and the Theory of Planned Behaviour." Journal of Applied Social Psychology 32: pp.1-20.

Ajzen, I. (2002b). Constructing a theory of planned behaviour questionnaire: conceptual and methodological considerations. Amherst, University of Massachusetts, Available at: http://www.people.umass.edu/aizen/pdf/tpb.measurement.pdf: [accessed June 2005].

Ajzen, I. (2005). Attitudes, personality and behaviour, 2nd edition. Milton Keynes, England, Open University Press/McGraw-Hill

Ajzen, I. and Fishbein, M. (1980). Understanding attitudes and predicting social behaviour New Jersey, Prentice-Hall, Inc.

Ajzen, I. and Fishbein, M. I. (2005). The influence of attitudes on behaviour. In: Albarracín, D., Johnson, B. T. and Zanna, M. P. (eds). The hand book of attitudes, pp 172-221, Mahwah NJ, Erlbaum

Altaf, M. A., Whittington, D., Jamal, H. and Kerry, V. K. (1993). "Rethinking rural water supply policy in Punjab, Pakistan." Water Resources Research 29(7): 1943-1954.

Babbie, E. (1990). Survey research methods, 2nd Edition. Belmont, CA: Wadesworth Publishing Company.

Baron, R. M. and Kenny, D. A. (1986). "The Moderator-Mediator Variable Distinction in Social Psychological Research: Conceptual, Strategic and Statistical Considerations." Journal of Personality and Social Psychology 51: 1173-1182.

Bohm, R. A., Essenburg, T. J. and Fox, W. F. (1993). "Sustainability of potable water services in the Philippines." Water Resources Research 29(7): 1955-1963.

Bourque, L. B. and Fielder, E. P. (2003). How to conduct self-administered and mail surveys, 2nd Edition Thousand Oaks, CA, Sage Publications.

Briscoe, J., De Castro, P. F., Griffin, C., North, J. and Olsen, O. (1990). "Toward equitable and sustainable rural water supplies: a contingent valuation study in Brazil." World Bank Economic Review 4(2): 115-134. 
Casey, J. F., Kahn, J. R. and Rivas, A. (2006). "Willingness to pay for improved water service in Manaus, Amazonas, Brazil." Ecological Economics 58: 365-372.

Cheung, S. F., Chan, D. K. S. and Wong, Z. S. Y. (1999). "Re-examining the theory of planned behaviour in understanding wastepaper recycling." Environment and Behaviour 31: 587-612.

Field, A. (2005). Discovering statistics using SPSS, 2nd edition. London, Sage Publications.

Fielding, K. S., Terry, D. J., Masser, B. M., Bordia, P. and Hogg, M. A. (2005). "Explaining landholder's decisions about riparian zone management: The role of behavioural, normative and control beliefs." Journal of Environmental Management 77(1): 12-21.

Francis, J. J., Eccles, P. M., Johnston, M., Walker, A., Grimshaw, J., Foy, R., Kaner, E. F., Smith, L. and Bonetti, D. (2004a). Constructing questionnaires based on the theory of planned behaviour: a manual for health services researchers. Newcastle, Centre for Health Services Research, University of Newcastle. Available at: http://www.rebeqi.org/ViewFile.aspx?itemID=212 [accessed 12 July 2006].

Griffin, C., Briscoe, J., Singh, B., Ramasubban, R. and Bhatia, R. (1995). "Contingent valuation and actual behaviour: predicting connections to new water systems in the state of Kerala, India." World Bank Economic Review 9(3): 373-395.

Gulyani, S., Talukdar, D. and Kariuki, R. M. (2005). Water for the urban poor: water markets, household demand, and service preferences in Kenya. World Bank Water Supply and Sanitation Sector Board Discussion Paper Series Paper No. 5. Washington, DC, World Bank.

Hopkins, O. S., Lauria, D. T. and Kolb, A. (2004). "Demand-based planning of rural water systems in developing countries." Journal of Water Resources Planning and Management 130(1): 44-52.

Hosmer, D. W. and Lemeshow, S. (2000). Applied logistic regression, 2nd edition. New York, Wiley.

Jenner, E. A., Watson, P. W. B., Miller, L., Jones, F. and Scott, G. M. (2002). "Explaining hand hygiene practice: an extended application of the theory of planned behaviour." Psychology, Health and Medicine 7(3): 311-326.

Kayaga, S. M., Calvert, J. and Sansom, K. (2003). "Paying for water services: effect of household characteristics." Utilities Policy 11(2003): 123-132.

Kayaga, S., Franceys, R. and Sansom, K. (2004). "Bill payment behaviour in urban water services: empirical data from Uganda." Journal of Water Supply: Research and Technology-AQUA 53(2004): 339-349.

Kenny, D. A. (2006). Mediation, [Online]. Available at: http://davidakenny.net/cm/mediate.htm [accessed August 16 2006].

Kline, P. (1999). The Handbook of psychological testing, 2nd edition. London, Routledge.

Lynne, G. D., Casey, C. F., Hodges, A. and Rahmani, M. (1995). "Conservation technology adoption decisions and the theory of planned behaviour." Journal of Economic Psychology 16: 581-598. 
Meyerhoff, J. (2006). "Stated willingness to pay as hypothetical behaviour: can attitudes tell us more?" Journal of Environmental Planning and Management 29(2): 209-226.

Miles, J. and Shevlin, M. (2001). Applying regression and correlation: a guide for students and researchers. London, Sage Publications

Mu, X., Whittington, D. and Briscoe, J. (1990). "Modelling village water demand behaviour: A discrete choice approach." Water Resources Research 26(4): 521-529.

Mugabi, J. (2007). Determinants of customer decisions to pay utility water bills promptly. PhD Thesis, Loughborough University, UK.

Mugabi, J., Kayaga, S., and Smout, I. (2007): “Why Water Utility Customers Don’t Pay their Bills Promptly”. Water Utility Management International, 2 (2) pp 17-20

Neuman, W. L. (1994). Social research methods: qualitative and quantitative approaches, 3rd edition. Needham Heights, MA: Allyn and Bacon.

Nunnally, J. and Bernstein (1994). Psychometric theory, 3rd edition. New York, McGrawHill.

Pattanayak, S. K., Van Den Berg, C., Yang, J. C. and Van Houtven, G. (2006). The use of willingness to pay experiments: estimating demand for piped water connections in Sri Lanka. World Bank Policy Research Working Paper 3818 January 2006. Washington DC, The World Bank.

Pedhazur, E. J. and Schmelkin, L. P. (1991). Measurement, design and analysis: an integrated approach. Hillsdale, NJ, Lawrence Erlbaum.

Perez-Pineda, F. (1999). Estimating the willingness to pay for water services in developing countries: A case study of the use of a contingent valuation survey in El Salvador, Central America. PhD Thesis, Purdue University.

Pett, M. A., Lackey, N. R. and Sullivan, J. J. (2003). Making sense of factor analysis: The use of factor analysis for instrument development in health care research. Thousand Oaks, Sage Publications, Inc.

Petty, R., Unnava, R. and Stratham, A. (1991). Theories of attitude change. In: Robertson, T. S. and Kassrjiann, H. H. (eds). Hand book of consumer behaviour, pp. 241-280. London, Prentice-Hall.

Sheeran, P. and Taylor, S. (1999). "Predicting intentions to use condoms: a meta-analysis and comparison of the theories of reasoned action and planned behaviour." Journal of Applied Social Psychology 29: pp. 1624-1675.

Singh, B., Ramasubban, R., Bhatia, R., Briscoe, J., Griffin, C. and Kim, C. (1993). "Rural water supply in Kerala, India: How to emerge from a low-level equilibrium trap." Water Resources Research 29(7): 1931-1942.

Tabachnick, B. G. and Fidell, L. S. (2001). Using multivariate statistics, 4th edition. Boston, Allyn \& Bacon.

Taylor, S. and Todd, P. (1995). "An integrated model of waste management behaviour: a test of household recycling and composting intentions." Environment and Behaviour 27: 603-630. 
Uganda Bureau of Statistics (2003). Uganda National Household Survey 2002/2003: Report on the Socio-economic Survey. Entebbe, Uganda National Bureau of Statistics.

Venkatachalam, L. (2006). "Factors influencing household willingness to pay for drinking water in peri-urban areas: a case study in the Indian context." Water Policy 8: 461473.

Whittington, D., Briscoe, J., Mu, X. and Barron, W. (1990). "Estimating the willingness to pay for water services in developing countries: A case study of the use of contingent valuation surveys in southern Haiti." Economic Development and Cultural Change 38(2): 293-311.

Whittington, D., Davis, J. and McClelland, E. (1998). "Implementing a demand-driven approach to community water supply planning: A case study of Lugazi, Uganda." Water International 23(3): 134-145

Whittington, D., Okorafor, A., Okore, A. and Mcphail, A. (1990). "Strategy for cost recovery in the rural water sector: A case study of Nsukka District, Anambra State, Nigeria." Water Resources Research 26(9): 1899-1913.

Whittington, D., Pattanayak, S. K., Yang, J. C. and Bal Kumar, K. C. (2002). "Household demand for improved piped water services: evidence from Kathmandu, Nepal." Water Policy 4(2002): 531-556.

World Bank Water Demand Research Team (1993). "The demand for water in rural areas: determinants and policy implications." The World Bank Research Observer 8 (1) 4770 . 